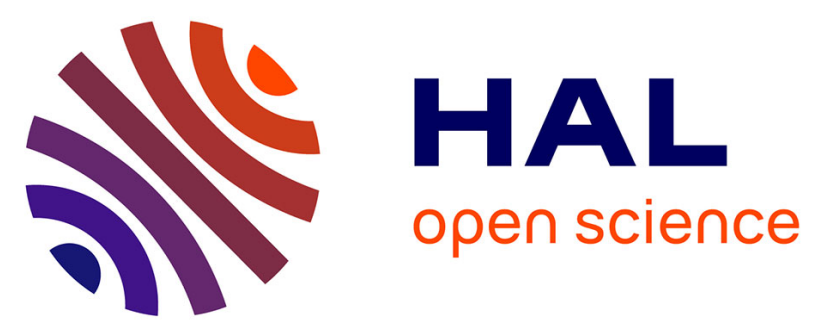

\title{
Dynamic Nuclear Polarization Efficiency Increased by Very Fast Magic Angle Spinning
}

Sachin R. Chaudhari, Dorothea Wisser, Arthur C. Pinon, Pierrick Berruyer, David Gajan, Paul Tordo, Olivier Ouari, Christian Reiter, Frank Engelke, Christophe Copéret, et al.

\section{To cite this version:}

Sachin R. Chaudhari, Dorothea Wisser, Arthur C. Pinon, Pierrick Berruyer, David Gajan, et al.. Dynamic Nuclear Polarization Efficiency Increased by Very Fast Magic Angle Spinning. Journal of the American Chemical Society, 2017, 139 (31), pp.10609-10612. 10.1021/jacs.7b05194 . hal-01576023

\section{HAL Id: hal-01576023 \\ https://hal.science/hal-01576023}

Submitted on 13 Jun 2018

HAL is a multi-disciplinary open access archive for the deposit and dissemination of scientific research documents, whether they are published or not. The documents may come from teaching and research institutions in France or abroad, or from public or private research centers.
L'archive ouverte pluridisciplinaire HAL, est destinée au dépôt et à la diffusion de documents scientifiques de niveau recherche, publiés ou non, émanant des établissements d'enseignement et de recherche français ou étrangers, des laboratoires publics ou privés. 


\section{Dynamic Nuclear Polarization Efficiency Increased by Very Fast Magic Angle Spinning}

Sachin R. Chaudhari, ${ }^{\dagger, \nabla}$ Dorothea Wisser, ${ }^{\dagger, \nabla}$ Arthur C. Pinon, ${ }^{\dagger}$ Pierrick Berruyer, ${ }^{\dagger}$ D David Gajan, ${ }^{\dagger}$ Paul Tordo, ${ }^{\S}$ Olivier Ouari, ${ }^{\S}$ Christian Reiter, ${ }^{\|}$Frank Engelke, ${ }^{\|}$Christophe Copéret, ${ }^{\perp \odot}$ Moreno Lelli, ${ }^{*}, \# \odot$ Anne Lesage, ${ }^{*}, \dagger$ and Lyndon Emsley*, $* 0$

${ }^{\dagger}$ Institut de Sciences Analytiques, Centre de RMN à Très Hauts Champs, Université de Lyon (CNRS/ENS Lyon/UCB Lyon 1), 69100 Villeurbanne, France

${ }^{\ddagger}$ Institut des Sciences et Ingénierie Chimiques, Ecole Polytechnique Fédérale de Lausanne, CH-1015 Lausanne, Switzerland

${ }^{\S}$ Aix-Marseille Université, CNRS, ICR UMR 7273, 13397 Marseille, France

"Bruker Biospin, 76287 Rheinstetten, Germany

${ }^{\perp}$ Department of Chemistry and Applied Biosciences, ETH Zürich, CH-8093 Zürich, Switzerland

${ }^{\#}$ Center for Magnetic Resonance, Department of Chemistry, University of Florence, 50019 Sesto Fiorentino (Firenze), Italy

Supporting Information

ABSTRACT: Dynamic nuclear polarization (DNP) has recently emerged as a tool to enhance the sensitivity of solid-state NMR experiments. However, so far high enhancements $(>100)$ are limited to relatively low magnetic fields, and DNP at fields higher than $9.4 \mathrm{~T}$ significantly drops in efficiency. Here we report solid-state Overhauser effect DNP enhancements of over 100 at 18.8 $\mathrm{T}$. This is achieved through the unexpected discovery that enhancements increase rapidly with increasing magic angle spinning (MAS) rates. The measurements are made using 1,3-bisdiphenylene-2-phenylallyl dissolved in o-terphenyl at $40 \mathrm{kHz}$ MAS. We introduce a source-sink diffusion model for polarization transfer which is capable of explaining the experimental observations. The advantage of this approach is demonstrated on mesoporous alumina with the acquisition of well-resolved DNP surfaceenhanced ${ }^{27} \mathrm{Al}$ cross-polarization spectra.

$\mathrm{D}$ ynamic nuclear polarization (DNP) has recently developed into a promising approach to greatly increase the sensitivity of solid-state NMR spectroscopy. ${ }^{1-3}$ DNP relies on microwave $(\mu \mathrm{w})$-driven polarization transfer from unpaired electrons to nearby nuclei and currently enables ${ }^{1} \mathrm{H}$ signal enhancements of more than 2 orders of magnitude at temperatures from 20 to $100 \mathrm{~K}$ and magnetic fields of up to $9.4 \mathrm{~T}^{4-10}$ and still relevant enhancements down to $4 \mathrm{~K}^{11}$ or up to room temperature. ${ }^{12}$ This has opened up new avenues for characterization in materials and life sciences, for example, for the detailed characterization of active sites on functional surfaces, for the elucidation of drug formulations or for the structural investigation of complex biological assemblies. ${ }^{13-20}$

Unpaired electrons as hyperpolarization sources are usually introduced into the sample as exogenous organic free radicals in a glass-forming solution. ${ }^{1,2}$ For magic angle spinning (MAS) DNP, the most efficient polarization transfer mechanism today is the cross effect $(\mathrm{CE})$, which is effective in particular for binitroxide radicals. Recent progress in the design of binitroxides has led to the introduction of AMUPol ${ }^{1,22}$ and TEKPol $^{7,23,24}$ like biradicals, which lead to proton enhancements of up to 250 at $9.4 \mathrm{~T}(400 \mathrm{MHz} / 263 \mathrm{GHz}), 100 \mathrm{~K}$, and $8 \mathrm{kHz}$ MAS frequency.

However, today high magnetic fields $(>14.1 \mathrm{~T})$ and fast MAS $(>15 \mathrm{kHz})$ are prerequisites for most applications in life sciences and materials. Unfortunately, the efficiency of the $\mathrm{CE}$ is predicted to scale with the inverse of the magnetic field strength. ${ }^{25,26}$ The observed drop in the enhancements with magnetic field is more than linear; ${ }^{27}$ e.g., enhancements of 10 $\mathrm{mM}$ AMUPol in a glycerol/water matrix are reduced to 130 at $14.1 \mathrm{~T}(600 \mathrm{MHz} / 395 \mathrm{GHz})$ and to 35 at $18.8 \mathrm{~T}(800 \mathrm{MHz} /$ $527 \mathrm{GHz}){ }^{21,28}$ Furthermore, binitroxide DNP efficiency also decreases at faster MAS rates, since the MAS modulation of the two electron frequencies results in depolarization processes and significant loss of overall observable nuclear spin polarization. ${ }^{26,29-32}$

Can et al. showed that, in contrast, the Overhauser effect (OE) has a favorable field dependence from 9.4 to $18.8 \mathrm{~T}^{33}$ They observed significant OE DNP using 1,3-bisdiphenylene-2phenylallyl (BDPA) in polystyrene, and sulfonated BDPA in a glycerol/water matrix. At $18.8 \mathrm{~T}$ and $8 \mathrm{kHz}$ MAS, we observed that BDPA in o-terphenyl (OTP) yields $\mathrm{OE}$ enhancements of up to 80 , the largest enhancement observed so far at this field. ${ }^{12}$ The favorable field dependence of BDPA has recently been rationalized by fluctuations of the hyperfine interaction. ${ }^{34}$

Here we report solid-state OE DNP enhancements of over 100 at $18.8 \mathrm{~T}$ using BDPA in OTP at $40 \mathrm{kHz}$ MAS. This is achieved through the unexpected discovery that enhancements increase rapidly with increasing MAS rates. Similar behavior is observed at 9.4 $\mathrm{T}$ and in 1,1,2,2-tetrachloroethane (TCE). We introduce a source-sink diffusion model for polarization transfer that is capable of explaining the experimental observations. The advantage of the approach is demonstrated

Received: May 19, 2017

Published: July 10, 2017 
with well-resolved DNP surface-enhanced ${ }^{27} \mathrm{Al}$ spectra on mesoporous alumina.

Figure 1a and Table $S 4$ give the ${ }^{1} \mathrm{H}$ OE DNP enhancements $\left(\varepsilon_{\mathrm{H}}\right)$ of $60 \mathrm{mM}$ BDPA in partially deuterated OTP $\left(d_{14}\right.$-OTP/

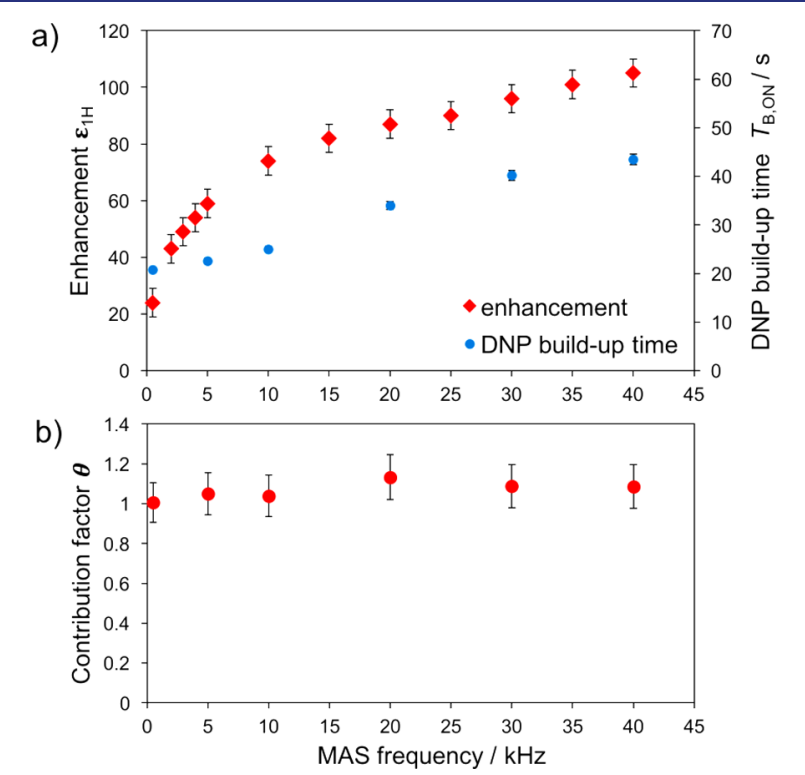

Figure 1. a) MAS frequency dependence of the ${ }^{1} \mathrm{H}$ OE DNP enhancements (red) and of ${ }^{1} \mathrm{H} T_{\mathrm{B}, \mathrm{ON}}$ (blue) at $18.8 \mathrm{~T}$ for the solvent resonance of $60 \mathrm{mM} \mathrm{BDPA}$ in $95 \% d_{14}$-OTP and 5\% OTP $\left.(w / w) . \mathrm{b}\right)$ Contribution factor as a function of MAS rate.

OTP, 95/5 w/w) as a function of the sample spinning frequency. The experiments were recorded using a $1.3 \mathrm{~mm}$ Bruker MAS DNP probe at $18.8 \mathrm{~T}$ and $\sim 128 \mathrm{~K}$ (see SI for details). At $0.5 \mathrm{kHz}$ MAS, an enhancement of 23 was observed, which increases with spinning rate. At $40 \mathrm{kHz}$, the maximum spinning frequency attainable with the probe, an enhancement of 105 was obtained. We note that at $10 \mathrm{kHz}$ MAS $\varepsilon_{\mathrm{H}}=74$, in agreement with previously reported values (80) using a $3.2 \mathrm{~mm}$ rotor under otherwise similar conditions. ${ }^{12}$ Figure 1a also reports ${ }^{1} \mathrm{H}$ DNP build-up times $T_{\mathrm{B}, \mathrm{ON}}{ }^{35}$ which significantly increase with the spinning frequency. As previously reported, ${ }^{12}$ the $T_{\mathrm{B}, \mathrm{ON}}$ are relatively long for BDPA in OTP. Experiments recorded at $9.4 \mathrm{~T}$ show a similar trend with spinning frequency, with maximum $\varepsilon_{\mathrm{H}} \approx 90$ (Table S5, Figures S8 and S9). Figures S10 and S11 report $\varepsilon_{\mathrm{H}}$ and $T_{\mathrm{B}, \mathrm{ON}}$ as a function of the MAS frequency for $60 \mathrm{mM}$ BDPA in TCE. Again, we observed that $\varepsilon_{\mathrm{H}}$ and $T_{\mathrm{B}, \mathrm{ON}}$ increase with increasing MAS rate, with $\varepsilon_{\mathrm{H}}=19.4$ at $9.4 \mathrm{~T}$ and $\varepsilon_{\mathrm{H}}=23$ at $18.8 \mathrm{~T}$, both at $40 \mathrm{kHz}$ spinning frequency. In all these experiments, $\varepsilon_{\mathrm{H}}$ and $T_{\mathrm{B}, \mathrm{ON}}$ show an almost linear correlation (Figure S12). Similar trends were observed in a completely degassed TCE solution (Figure S13), and for the solid effect (SE) of BDPA in OTP (Figure S14).

Figure $1 \mathrm{~b}$ shows the contribution factor $\theta$, which is defined as the ratio of the signal intensities per unit of mass recorded in the absence of $\mu \mathrm{w}$ irradiation for solutions with and without the polarizing agent (eq 1 in the SI). ${ }^{36}$ It accounts for signal reduction in the presence of paramagnetic species without $\mu \mathrm{w}$ irradiation, due to paramagnetic effects (quenching, depolarization, anisotropy of the hyperfine interactions, etc.) induced by the radical. A high contribution factor close to unity is favorable for a high overall sensitivity gain (eq 2 in the SI). ${ }^{29,30,36,37}$ Here, we find that the contribution factor remains almost constant at around 1.0 over the whole spinning frequency range. Similar data were obtained at $9.4 \mathrm{~T}$ (Figure S15a). This behavior is in contrast to that of the $\mathrm{CE}$ in binitroxides, where $\theta$ decreases significantly with increasing MAS frequency due to depolarization, e.g., to 0.46 at $40 \mathrm{kHz}$ MAS with $10 \mathrm{mM}$ AMUPol in glycerol/water. ${ }^{28}$ A stable high contribution factor is in line with expectations, since BDPA is not an efficient paramagnetic relaxation agent (confirmed by the long $T_{\mathrm{B}, \mathrm{ON}}$ ) and since depolarization processes are absent in isotropic narrow-line radicals.

Even though the $T_{\mathrm{B}, \mathrm{ON}}$ values of the BDPA/OTP system are longer than in most binitroxide radicals, in the bulk radical solution the overall sensitivity at $18.8 \mathrm{~T}$ of BDPA/OTP is higher than for $10 \mathrm{mM}$ AMUPol in a glycerol/water matrix under otherwise similar conditions (see Table S3).

If we assume that the intrinsic efficiency of Overhauser DNP does not depend significantly on MAS rate in this spinning regime, then the spinning speed dependence of $\varepsilon_{\mathrm{H}}$ and $T_{\mathrm{B}, \mathrm{ON}}$ observed here can be explained in terms of ${ }^{1} \mathrm{H}$ spin diffusion dynamics. Spin diffusion models have previously shown that the enhancement depends on the polarization time if the spin diffusion rate from the radical source to the bulk of the sample is the rate-determining step. ${ }^{13,35,38} \mathrm{~A}$ detailed description for different cases is given in ref 35 . We observe such behavior in the BDPA/OTP system (Figure S16), suggesting that the dependence of $\varepsilon_{\mathrm{H}}$ and $T_{\mathrm{B}, \mathrm{ON}}$ on the spinning frequency could be modeled in a similar fashion. The spinning speed behavior would then be due to progressive isolation of the paramagnetic relaxation sinks as the spin diffusion constant is reduced with increasing spinning rates. ${ }^{39,40}$ If the BDPA is the relaxation sink (as is often assumed in models for polarization of frozen solutions of binitroxides ${ }^{35}$ ), then we cannot reproduce an increase of the enhancement with faster spinning (see Figure $\mathrm{S} 17$ ) at the radical concentrations relevant here (tens of $\mathrm{mM}$ ). However, as mentioned above, BDPA is not an efficient relaxing agent, and so we extend the previous models to include separate polarization sources and relaxation sinks (Figure 2a). The sinks could be traces of paramagnetic impurities or of dissolved oxygen, ${ }^{39,41,42}$ surrounded by a sphere in which the longitudinal relaxation times are short. A detailed explanation of the model and the simulations is given in the SI. Within this hypothesis, we were able to successfully reproduce the experimentally observed ${ }^{1} \mathrm{H}$ OE enhancements and build up times as a function of the MAS rate (Figure 2b). If the model is correct, it shows that even a very low concentration of impurities (here $14 \mu \mathrm{M}$ ) can generate a MAS dependence in the DNP enhancements. Fast sample spinning decouples the relaxation sinks from the bulk solution, which increases the overall apparent build-up time constant, and in turn leads to more efficient propagation of the hyperpolarization from the BDPA sources. The model also predicts that $\varepsilon_{\mathrm{H}}$ increases with increasing polarization time, which is expected for a system having two domains, one being a polarized domain and the other being a relaxation sink with longer and shorter relaxation times, respectively, ${ }^{13,35}$ and this agrees with experiment (Figure S16). We note that the source-sink model is in principle general, and a possible further increase in the enhancement is expected at higher MAS frequencies. Recently, we observed a MAS dependence of the $T_{\mathrm{B}, \mathrm{ON}}$ for AMUPol in a water/glycerol matrix, though the observed effect is much smaller due to shorter $T_{\mathrm{B}, \mathrm{RS}}{ }^{28}$

The practicability of this new approach and the importance of high enhancements at high fields is illustrated here in the context of DNP surface-enhanced NMR spectroscopy (DNP 


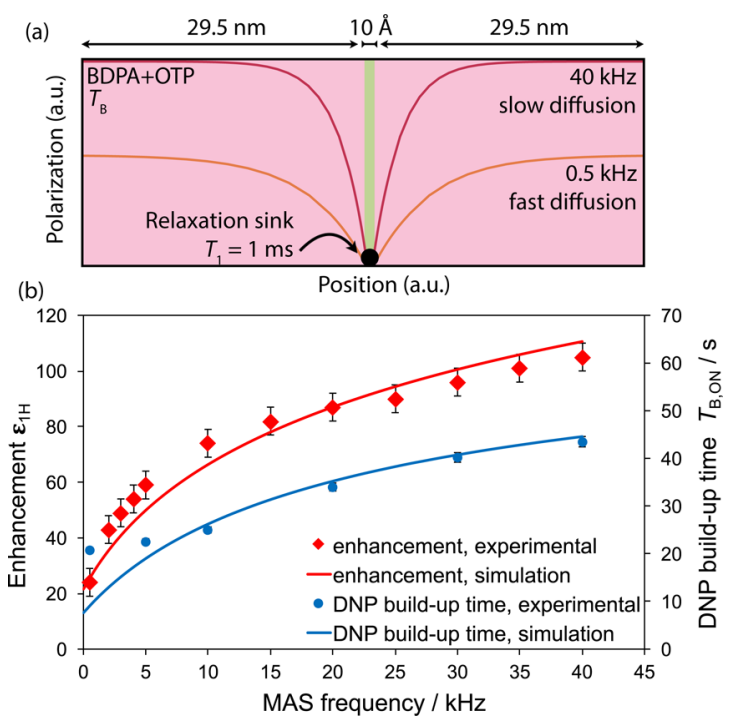

Figure 2. a) Schematic model for spin diffusion in the sample: BDPA molecules are assumed to be randomly distributed in an OTP matrix (pink). The diffusion constant $D$ depends on the MAS rate. Relaxation sinks (green) are included with a short $T_{1}$ at low concentration (here $14 \mu \mathrm{M}$ ), leading to a mean distance between the sinks of $60 \mathrm{~nm}$. b) Comparison of experimental and simulated results at $18.8 \mathrm{~T}$. $T_{\mathrm{B}, \mathrm{RS}}$ is the modeled build-up time of the BDPA/OTP solution in the absence of sinks. In the fit $T_{\mathrm{B}, \mathrm{RS}}$ is taken to be $73 \mathrm{~s}, T_{1, \text { sink }}=1 \mathrm{~ms}, \varepsilon_{0}=260$ and $D$ varies from $1.54 \times 10^{-4} \mu \mathrm{m}^{2} / \mathrm{s}$ at $0.5 \mathrm{kHz}$ MAS to $0.080 \times 10^{-4}$ $\mu \mathrm{m}^{2} / \mathrm{s}$ at $40 \mathrm{kHz}$. The same parameters were used for fitting both the enhancement and $T_{\mathrm{B}, \mathrm{ON}}$. Details in the SI.

SENS), ${ }^{2,3}$ where quadrupolar nuclei at surfaces are of particularly high interest, playing key roles in many functional inorganic or hybrid materials. Several ${ }^{27} \mathrm{Al}$ spectra have been reported in this context on a variety of mesoporous and nanoparticulate systems. ${ }^{4-46}$ In this case, spectral resolution is limited by second-order quadrupolar shifts and broadenings, and resolution and sensitivity increase with $B_{0}{ }^{2}$. In parallel fast MAS separates spinning sidebands from the isotropic shift range and provides spectra from which isotropic chemical shifts, quadrupolar couplings and asymmetry parameters can be reliably extracted. DNP at high magnetic fields and fast MAS is thus particularly attractive for surface quadrupolar NMR.

Figure 3 shows ${ }^{27} \mathrm{Al}$ DNP-SENS spectra of mesoporous alumina at $18.8 \mathrm{~T}$ with MAS at 10 and $40 \mathrm{kHz}$. The sample was

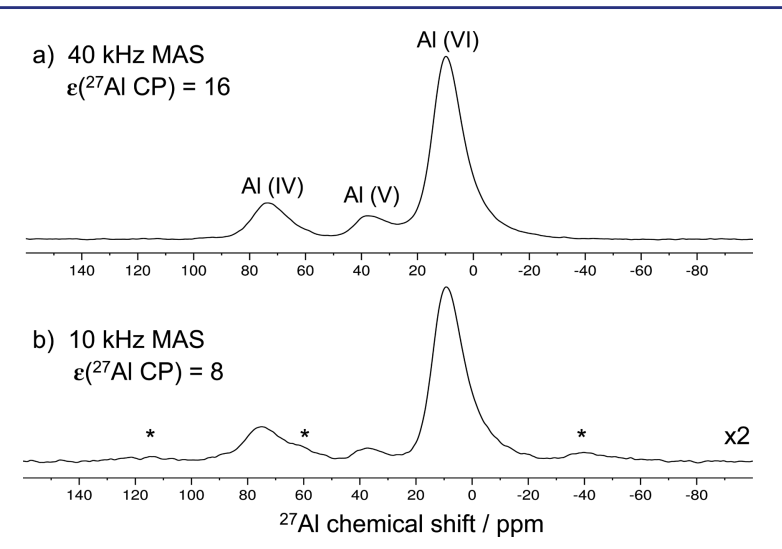

Figure 3. OE DNP-enhanced ${ }^{27} \mathrm{Al}$ cross-polarization (CP) MAS spectra of mesoporous alumina at $18.8 \mathrm{~T}$ at (a) $40 \mathrm{kHz}$ and (b) 10 $\mathrm{kHz}$ MAS. prepared by impregnation with $40 \mathrm{mM}$ BDPA in $95 \% d_{14}$-OTP and 5\% OTP (see SI for details). OE enhancements of $\varepsilon_{\mathrm{H} \text { (solvent) }}$ $=60$ and $\varepsilon^{27} \mathrm{Al}(\mathrm{CP})=16$ were measured at $40 \mathrm{kHz}$ MAS on the solvent and on the ${ }^{27} \mathrm{Al}$ resonances, respectively (Figure S18). At $10 \mathrm{kHz}$ MAS, significantly lower values were obtained $\left(\varepsilon_{\mathrm{H}(\text { solvent })}=37\right.$ and $\left.\varepsilon^{27} \mathrm{Al}(\mathrm{CP})=8\right)$, as expected from above. We note that, as expected, DNP at fast MAS yields high sensitivity spectra free of spinning sidebands and spectral distortions. The quadrupolar parameters extracted from the spectrum are given in Table S6.

In conclusion, we have obtained solid-state Overhauser effect DNP enhancements of over 100 at $18.8 \mathrm{~T}$ using BDPA in OTP at $40 \mathrm{kHz}$ MAS. This is, to the best of our knowledge, the highest $\varepsilon_{\mathrm{H}}$ achieved so far at this magnetic field. We found that enhancements increase rapidly with increasing MAS rates. This is consistent with a theoretical description using a source-sink diffusion model. The study shows that BDPA in OTP forms an efficient polarizing matrix for DNP at fast MAS, as exemplified on a model sample of mesoporous alumina. The BDPA/OTP pair at fast MAS will open new perspectives, notably for surfaces which may react with TEMPO-based radicals, and should stimulate the development of other narrow line radicals for OE DNP.

\section{ASSOCIATED CONTENT}

\section{Supporting Information}

The Supporting Information is available free of charge on the ACS Publications website at DOI: 10.1021/jacs.7b05194.

Additional experimental details and data; MatLab Code for numerical calculations; Figures S1-S18, Tables S1S6, and eqs $1-16$ (PDF)

\section{AUTHOR INFORMATION}

\section{Corresponding Authors}

*moreno.lelli@unifi.it

*anne.lesage@ens-lyon.fr

*lyndon.emsley@epfl.ch

\section{ORCID}

Pierrick Berruyer: 0000-0003-1783-6034

Christophe Copéret: 0000-0001-9660-3890

Moreno Lelli: 0000-0002-7042-2335

Lyndon Emsley: 0000-0003-1360-2572

\section{Author Contributions}

$\nabla_{\text {S.R.C. and D.W. contributed equally. }}$

\section{Notes}

The authors declare no competing financial interest.

\section{ACKNOWLEDGMENTS}

We are grateful to Maxence Valla for the preparation of the mesoporous alumina. Financial support was received from the ERC Advanced Grant No. 320860, EQUIPEX (contract ANR10-EQPX-47-01), and the ANR (contract ANR15-CE29-002202). D.W. gratefully acknowledges financial support from the Deutsche Forschungsgemeinschaft (WI 4934/1-1).

\section{REFERENCES}

(1) Ni, Q. Z.; Daviso, E.; Can, T. C.; Markhasin, E.; Jawla, S.; Swager, T. M.; Temkin, R. J.; Herzfeld, J.; Griffin, R. G. Acc. Chem. Res. 2013, 46, 1933.

(2) Rossini, A. J.; Zagdoun, A.; Lelli, M.; Lesage, A.; Copéret, C.; Emsley, L. Acc. Chem. Res. 2013, 46, 1942. 
(3) Lesage, A.; Lelli, M.; Gajan, D.; Caporini, M. A.; Vitzthum, V.; Miéville, P.; Alauzun, J.; Roussey, A.; Thieuleux, C.; Mehdi, A.; Bodenhausen, G.; Copéret, C.; Emsley, L. J. Am. Chem. Soc. 2010, 132, 15459.

(4) Thurber, K. R.; Yau, W.-M.; Tycko, R. J. Magn. Reson. 2010, 204, 303.

(5) Kubicki, D. J.; Rossini, A. J.; Purea, A.; Zagdoun, A.; Ouari, O.; Tordo, P.; Engelke, F.; Lesage, A.; Emsley, L. J. Am. Chem. Soc. 2014, $136,15711$.

(6) Jagtap, A. P.; Geiger, M. A.; Stoppler, D.; Orwick-Rydmark, M.; Oschkinat, H.; Sigurdsson, S. T. Chem. Commun. 2016, 52, 7020.

(7) Kubicki, D. J.; Casano, G.; Schwarzwälder, M.; Abel, S.; Sauvée, C.; Ganesan, K.; Yulikov, M.; Rossini, A. J.; Jeschke, G.; Copéret, C.; Lesage, A.; Tordo, P.; Ouari, O.; Emsley, L. Chem. Sci. 2016, 7, 550.

(8) Lee, D.; Bouleau, E.; Saint-Bonnet, P.; Hediger, S.; De Paëpe, G. J. Magn. Reson. 2016, 264, 116.

(9) Matsuki, Y.; Idehara, T.; Fukazawa, J.; Fujiwara, T. J. Magn. Reson. 2016, 264, 107.

(10) Thurber, K.; Tycko, R. J. Magn. Reson. 2016, 264, 99.

(11) Lund, A.; Hsieh, M. F.; Siaw, T. A.; Han, S. I. Phys. Chem. Chem. Phys. 2015, 17, 25449.

(12) Lelli, M.; Chaudhari, S. R.; Gajan, D.; Casano, G.; Rossini, A. J.; Ouari, O.; Tordo, P.; Lesage, A.; Emsley, L. J. Am. Chem. Soc. 2015, $137,14558$.

(13) Rossini, A. J.; Zagdoun, A.; Hegner, F.; Schwarzwälder, M.; Gajan, D.; Copéret, C.; Lesage, A.; Emsley, L. J. Am. Chem. Soc. 2012, 134, 16899.

(14) Presti, C.; Thankamony, A. S. L.; Alauzun, J. G.; Mutin, P. H.; Carnevale, D.; Lion, C.; Vezin, H.; Laurencin, D.; Lafon, O. J. Phys. Chem. C 2015, 119, 12408.

(15) Märker, K.; Pingret, M.; Mouesca, J.-M.; Gasparutto, D.; Hediger, S.; De Paëpe, G. J. Am. Chem. Soc. 2015, 137, 13796.

(16) Becker-Baldus, J.; Bamann, C.; Saxena, K.; Gustmann, H.; Brown, L. J.; Brown, R. C. D.; Reiter, C.; Bamberg, E.; Wachtveitl, J.; Schwalbe, H.; Glaubitz, C. Proc. Natl. Acad. Sci. U. S. A. 2015, 112, 9896.

(17) Frederick, K. K.; Michaelis, V. K.; Corzilius, B.; Ong, T. C.; Jacavone, A. C.; Griffin, R. G.; Lindquist, S. Cell 2015, 163, 620.

(18) Presti, C.; Thankamony, A. S. L.; Alauzun, J. G.; Mutin, P. H.; Carnevale, D.; Lion, C.; Vezin, H.; Laurencin, D.; Lafon. J. Phys. Chem. C 2015, 119, 12408.

(19) Berruyer, P.; Lelli, M.; Conley, M. P.; Silverio, D. L.; Widdifield, C. M.; Siddiqi, G.; Gajan, D.; Lesage, A.; Copéret, C.; Emsley, L. J. Am. Chem. Soc. 2017, 139, 849.

(20) Pump, E.; Viger-Gravel, J.; Abou-Hamad, E.; Samantaray, M. K.; Hamzaoui, B.; Gurinov, A.; Anjum, D. H.; Gajan, D.; Lesage, A.; Bendjeriou-Sedjerari, A.; Emsley, L.; Basset, J.-M. Chem. Sci. 2017, 8, 284.

(21) Sauvée, C.; Rosay, M.; Casano, G.; Aussenac, F.; Weber, R. T.; Ouari, O.; Tordo, P. Angew. Chem., Int. Ed. 2013, 52, 10858.

(22) Sauvée, C.; Casano, G.; Abel, S.; Rockenbauer, A.; Akhmetzyanov, D.; Karoui, H.; Siri, D.; Aussenac, F.; Maas, W.; Weber, R. T.; Prisner, T.; Rosay, M.; Tordo, P.; Ouari, O. Chem. - Eur. J. 2016, 22, 5598.

(23) Zagdoun, A.; Casano, G.; Ouari, O.; Lapadula, G.; Rossini, A. J.; Lelli, M.; Baffert, M.; Gajan, D.; Veyre, L.; Maas, W. E.; Rosay, M.; Weber, R. T.; Thieuleux, C.; Copéret, C.; Lesage, A.; Tordo, P.; Emsley, L. J. Am. Chem. Soc. 2012, 134, 2284.

(24) Zagdoun, A.; Casano, G.; Ouari, O.; Schwarzwaelder, M.; Rossini, A. J.; Aussenac, F.; Yulikov, M.; Jeschke, G.; Copéret, C.; Lesage, A.; Tordo, P.; Emsley, L. J. Am. Chem. Soc. 2013, 135, 12790.

(25) Hu, K. N.; Bajaj, V. S.; Rosay, M.; Griffin, R. G. J. Chem. Phys. 2007, 126, 044512.

(26) Mentink-Vigier, F.; Akbey, Ü.; Oschkinat, H.; Vega, S.; Feintuch, A. J. Magn. Reson. 2015, 258, 102.

(27) Mance, D.; Gast, P.; Huber, M.; Baldus, M.; Ivanov, K. L. J. Chem. Phys. 2015, 142, 234201.
(28) Chaudhari, S. R.; Berruyer, P.; Gajan, D.; Reiter, C.; Engelke, F.; Silverio, D.; Copéret, C.; Lelli, M.; Lesage, A.; Emsley, L. Phys. Chem. Chem. Phys. 2016, 18, 10616.

(29) Thurber, K. R.; Tycko, R. J. Chem. Phys. 2014, 140, 184201.

(30) Thurber, K. R.; Tycko, R. J. Chem. Phys. 2012, 137, 084508.

(31) Mentink-Vigier, F.; Paul, S.; Lee, D.; Feintuch, A.; Hediger, S.; Vega, S.; De Paëpe, G. Phys. Chem. Chem. Phys. 2015, 17, 21824.

(32) Mentink-Vigier, F.; Vega, S.; De Paëpe, G. Phys. Chem. Chem. Phys. 2017, 19, 3506

(33) Can, T. V.; Caporini, M. A.; Mentink-Vigier, F.; Corzilius, B.; Walish, J. J.; Rosay, M.; Maas, W. E.; Baldus, M.; Vega, S.; Swager, T. M.; Griffin, R. G. J. Chem. Phys. 2014, 141, 064202.

(34) Pylaeva, S.; Ivanov, K. L.; Baldus, M.; Sebastiani, D.; Elgabarty, H. J. Phys. Chem. Lett. 2017, 8, 2137.

(35) Pinon, A. C.; Schlagnitweit, J.; Berruyer, P.; Rossini, A. J.; Lelli, M.; Socie, E.; Tang, M.; Pham, T. N.; Lesage, A.; Schantz, S.; Emsley, L. J. Phys. Chem. C 2017, DOI: 10.1021/acs.jpcc.7b04438.

(36) Rossini, A. J.; Zagdoun, A.; Lelli, M.; Gajan, D.; Rascón, F.; Rosay, M.; Maas, W. E.; Copéret, C.; Lesage, A.; Emsley, L. Chem. Sci. 2012, 3, 108.

(37) Takahashi, H.; Lee, D.; Dubois, L.; Bardet, M.; Hediger, S.; De Paëpe, G. Angew. Chem., Int. Ed. 2012, 51, 11766.

(38) van der Wel, P. C.; Hu, K. N.; Lewandowski, J.; Griffin, R. G. J. Am. Chem. Soc. 2006, 128, 10840.

(39) Kessemeier, H.; Norberg, R. E. Phys. Rev. 1967, 155, 321.

(40) Maricq, M. M.; Waugh, J. S. J. Chem. Phys. 1979, 70, 3300.

(41) Hayashi, S. Solid State Nucl. Magn. Reson. 1994, 3, 323.

(42) Hayashi, S.; Akiba, E. Solid State Nucl. Magn. Reson. 1995, 4, 331.

(43) Vitzthum, V.; Mieville, P.; Carnevale, D.; Caporini, M. A.; Gajan, D.; Copéret, C.; Lelli, M.; Zagdoun, A.; Rossini, A. J.; Lesage, A.; Emsley, L.; Bodenhausen, G. Chem. Commun. 2012, 48, 1988.

(44) Lee, D.; Duong, N. T.; Lafon, O.; De Paëpe, G. J. Phys. Chem. C 2014, 118, 25065.

(45) Valla, M.; Rossini, A. J.; Caillot, M.; Chizallet, C.; Raybaud, P.; Digne, M.; Chaumonnot, A.; Lesage, A.; Emsley, L.; van Bokhoven, J. A.; Copéret, C. J. Am. Chem. Soc. 2015, 137, 10710.

(46) Mouat, A. R.; George, C.; Kobayashi, T.; Pruski, M.; van Duyne, R. P.; Marks, T. J.; Stair, P. C. Angew. Chem., Int. Ed. 2015, 54, 13346. 